\title{
Genotype and environment interactively determine the magnitude, directionality, and abolition of defensive burying in mice
}

\author{
JOHN C. MAGGIO and DAVID B. HARDER \\ Florida State University, Tallahassee, Florida
}

\begin{abstract}
Genotypic and environmental contributions to the defensive burying response were examined by testing four sublines of two inbred strains of mice in test chambers of three different lengths. Burying was found to be dependent on both the particular subline tested and the length of the test chamber employed. For two sublines, specific increases in the length of the test chamber resulted in the complete abolition of defensive burying. A third subline never displayed defensive burying, and the fourth buried in all three chamber-length conditions. Sex differences in burying were never observed. Rather than being viewed as a species-specific defensive reaction, it was proposed that defensive burying should more appropriately be viewed as a genotypically dependent response, the expression of which is contingent on the specific environmental context in which an aversive stimulus is encountered. Apparent conflicts in the defensive-burying literature were reconciled in accordance with this interpretation.
\end{abstract}

Considerable attention has now been focused on a recently rediscovered behavioral response exhibited by some rodent species. First described by Hudson (1950) and subsequently termed "defensive burying" (Pinel \& Treit, 1978), the response is characterized in findings demonstrating that some rodents, under certain conditions, will push and spray a provided burying material (e.g., sand, wood, shavings, sawdust) toward a previously encountered aversive stimulus (e.g., shock prod, flash bulb), frequently covering it, but not an identical control stimulus (Pinel \& Treit, 1978, 1979; Terlecki, Pinel, \& Treit, 1979; Treit, Terlecki, \& Pinel, 1980). Not surprisingly, the defensive-burying response to aversive stimulation has generated substantial interest for a number of reasons. First, it can be elicited by a variety of aversive stimuli affecting diverse sensory modalities (Davis, Whiteside, Dickson, Heck, \& McKnab, 1982; Terlecki et al., 1979; Wilkie, MacLennan, \& Pinel, 1979). Second, it is employed as an unconditioned response to some stimuli (Owings, Borchert, \& Virginia, 1977; Pinel, Hoyer, \& Terlecki, 1980; Poling, Cleary, \& Monaghan, 1981; Terlecki et al., 1979) yet is readily conditionable to other stimuli in a single trial (Pinel, Treit, \& Wilkie, 1980; Terlecki et al., 1979; Wilkie et al., 1979). Third, the response may have survival value in naturalistic settings (Owings \& Coss, 1978). Further, the finding of

We wish to thank Glayde Whitney and Debbie Brock for their helpful comments and technical assistance in the preparation of this manuscript. The authors' mailing address is: Department of Psychology, Florida State University, Tallahassee, Florida 32306. a new, robust response to aversive stimulation that is exhibited only if burying material is provided also has important implications regarding responselimiting constraints (see Holland, 1977) typically placed on animal subjects in traditional (i.e., no burying material provided) escape/avoidance learning paradigms (Pinel \& Treit, 1978).

The importance of the defensive-burying response in naturalistic settings remains problematical. Indeed, it is difficult to envision rodents burying every aversive stimulus they encounter in nature since many of such stimuli are simply not buriable (e.g., large toxic plants, contaminated bodies of water, large decaying carcasses of other species). Furthermore, in their natural habitats rodents are probably rarely required to remain as close to a highly aversive stimulus (cf. Owings \& Coss, 1978) as they are in laboratory paradigms. Thus, it is entirely possible that constraints inherent to the test chambers employed in typical laboratory defensive-burying paradigms, such as limited directions and distances accessible for flight (Pinel, Treit, Ladak, \& MacLennan, 1980), the geometric shape of the test chamber (Davis, Moore, Cowen, Thurston, \& Maggio, 1982), or the specific location of the shock prod in the test chamber (Modaresi, 1982), may themselves contribute to the adoption of a defensive-burying strategy. In less restricted conditions, other defensive strategies (Bolles, 1970) might alternatively be employed.

A number of investigators have recently examined the effects on defensive burying of varying the size of the test chamber. Pinel, Treit, Ladak, and MacLennan (1980) reported that increasing the size of the 
test chamber or providing a safe compartment away from the shock area reduced, but did not abolish, the defensive burying of a shock prod by rats. Chambersize dependent reductions in defensive burying have also been obtained for gerbils tested in round chambers (Davis, Moore, et al., 1982). Conflictingly, Peacock and Wong (1982) reported that in a twoprod situation (i.e., shock and control prods) the amount of time rats spent burying either prod was unaffected by doubling the size of the test chamber. Poling et al. (1981) also found that increasing the size of the test chamber did not abolish either conditioned or unconditioned burying. One possible explanation of why the test chamber size increases employed in previous experiments did not result in complete abolition of burying is that the maximum distance accessible to subjects for flight from the shock source might not have been great enough. Total abolition of the burying response in favor of an alternative flight/ avoidance strategy might be predicted provided a large enough distance for flight from the shock prod (relative to the size of the animal) is available. Thus, the maximal distance for flight, rather than total area of the test chamber, may be the determining factor of whether burying will or will not occur.

Along with environmental factors, genetic contributions may also be important in determining whether defensive burying will occur. Unfortunately, genetic contributions to defensive burying have only peripherally been investigated, and only recently have species differences and within-species strain differences been documented (Davis, Moore, et al., 1982; Davis, Whiteside, et al., 1981; McKim \& Lett, 1979; Tarte \& Oberdieck, 1982; Treit et al., 1980; Whillans \& Shettleworth, 1981). If genetic factors do play an important role in defensive burying, the degree of genotypic similarity may be reflected by similarities in defensive-burying patterns. Thus, one might predict that (1) sublines of the same strain, possessing a high degree of genotypic similarity, should be more similar in their defensive-burying patterns than sublines of different strains, and (2) genetically divergent sublines of the same strain may also display different burying patterns.

The purpose of the present investigation was twofold. Our first intent was to assess whether mice would display decrements in defensive burying as a function of increasing the available distance for flight from an aversive stimulus. Furthermore, could the burying response be totally abolished in favor of fleeing if the distance available for flight was great enough? A second and equally important intent was to determine whether phenotypic differences in defensive burying were based on genotypic differences. If so, would such differences be dependent on the distance parameters described above?

\section{METHOD}

\section{Subjects}

Because a wide body of literature currently exists on DBA and C57 mice, and because both are commonly used in genetic and behavioral research, we chose, in the present experiment, to use two genotypically different samples of each. The parent stock of animals from which all subjects were derived was developed at and obtained from the mouse colony of B. Ginsburg and S. Maxson, Behavioral Genetics Laboratory, The University of Connecticut (Storrs, Connecticut). Parental animals consisted of two inbred strains of mice (Mus musculus), the DBA/1/Bg strain and the C57BL/10/Bg strain (see Selmanoff, Maxson, \& Ginsburg, 1976, for strain origins and histories). The $\mathrm{DBA} / 1 / \mathrm{Bg}_{\mathrm{g}}$ strain was represented by two sublines previously designated as $D B A / 1$ subline $H$ and DBA/1 subline I (Ginsburg, Vigue, Larson, \& Maxson, 1981) and herein referred to as D-H and D-I, respectively. Both had been separated and inbred for over 35 generations prior to our acquisition (Ginsburg et al., 1981). The C57BL/10/Bg strain was represented by one inbred subline, the C57BL/10-Y (Maxson, Ginsburg, \& Trattner, 1979), and also by a heterogeneous stock of mice derived from sublines previously designated as C57BL/10/Bg sublines A, B, and H (Maxson, Note 1). These "sublines" are herein referred to as $C-Y$ and $C 10$, respectively. Genotypic and behavioral differences between the within-strain sublines employed in this experiment have been elucidated elsewhere (Ginsburg et al., 1981; Maxson et al., 1979). Briefly, the D-H subline differs from the D-I subline in that males of the former possess significantly longer Y-chromosome than males of the latter (Ginsburg et al., 1981). Relative to the two C57 sublines, however, males of both DBA sublines have short Y-chromosomes and display higher intermale aggression (Ginsburg et al., 1981; Selmanoff et al., 1976). The $\mathrm{C}$-Y subline is a stock congenic with the $\mathrm{C} 10$ subline, but differs in that C-Y males carry a DBA/1/Bg Y-chromosome (Maxson et al., 1979).

On arrival of a representative sample of male and female mice of each subline, all animals were individually housed in transparent $29 \times 18 \times 13 \mathrm{~cm}$ plastic cages with approximately 2 level centimeters of clean wood shavings (Beta-chips, Northeastern Products Corp., Warrensburg, N.Y.) for bedding and a wire-mesh top supporting a water bottle and food. These animals and their subsequent progeny were maintained in a temperature- and humiditycontrolled room at $24^{\circ} \pm 1^{\circ} \mathrm{C}$ under a $12: 12$ light/dark cycle (lights on at $0800 \mathrm{~h}$ EST). Food (Purina Rodent Lab Chow 5001) and water were provided ad lib to all animals for the duration of the experiment.

Following approximately 2 weeks of undisturbed individual housing, within-subline mating pairs were established by placing one male and one female into a clean mouse cage identical to those described above. Mating pairs were then left undisturbed aside from general cage maintenance and the weaning of litters.

Two hundred and forty $G_{1}$ offspring of the above mating pairs served as subjects ( 30 males and 30 females/subline). Only offspring of the first five litters/mating pair were used. All subjects were weaned at 23 days of age and were group housed with like-sex littermates in clean cages identical to those previously described. At $\mathbf{5 0}$ days of age, each subject was individually housed and then not disturbed until 80 days of age. Between 80 and 95 days of age, prior to their use in this experiment, all subjects were used in another, nonrelated, experiment entailing the recording of their emission of ultrasonic vocalizations during a 3-min exposure to both a male and a female conspecific of the same subline. All subjects were 85-120 days of age when used in the current experiment.

\section{Experimental Design}

A between-subjects experimental design was employed with each subject being tested only once. Of the $\mathbf{3 0}$ male and $\mathbf{3 0}$ female mice comprising each of the four sublines, 15 males and 15 females served as shock-treatment subjects and 15 males and 15 females served as nonshocked controls. Treatment and control groups 
were further subdivided in accordance with their being tested in one of 3 different test chamber conditions $(n=5$ males and 5 females/chamber condition). Thus, a total of 240 mice were tested: 5 males and 5 females per subline $\times 2$ sublines per strain $\times$ 2 strains $\times 3$ test chamber conditions $\times 2$ experimental treatment groups.

\section{Apparatus}

The test chamber consisted of a standard Plexiglas straight runway $(9.3 \mathrm{~cm}$ wide $\times 12.4 \mathrm{~cm}$ deep on the inside) with a removable Plexiglas ceiling and an aluminum floor. The length of the runway was 30,91 , or $152 \mathrm{~cm}$, corresponding to the three different chamber-length conditions subsequently referred to as conditions $1^{\prime}, 3^{\prime}$, and $5^{\prime}$, respectively. The overall surface areas of the floor were 283, 85, ${ }^{1}$ and $1,417 \mathrm{~cm}^{2}$, respectively. Prior to the testing of each subject, the floor of the entire test chamber was covered with a level 2-cm layer of clean bedding (i.e., burying material) identical to that in which the animals had been housed since birth.

A single prod $(0.5-\mathrm{cm}$ diam) was mounted on one end-wall of the runway so that its diametric center was $3.75 \mathrm{~cm}$ above the runway floor and $1.75 \mathrm{~cm}$ above the bedding layer. The prod projected $3.0 \mathrm{~cm}$ into the runway, midway between and parallel to the two long side walls. The prod consisted of four wires firmly secured at one end by a Teflon insulator so that no two adjacent wires made contact. The other ends of the wires projected out of the runway through a rubber stopper and served as terminals to which the shock source was attached. For shocked subjects, the prod was electrified via a Grason-Stadler shock generator (Model E6070B) so that when any two adjacent prod wires were simultaneously contacted, a 3-mA shock was automatically delivered through the prod for the duration of the contact.

In order to minimize the possible confounding effects of chamber-size-dependent shock latency differences on postshock burying measures, the test chamber was modified so that shocktreatment subjects of all three chamber-length conditions were restricted to the $30 \mathrm{~cm}$ of runway closest to the prod until they received the initial shock. This modification entailed using a sliding Plexiglas "door" ( $9.3 \mathrm{~cm}$ wide) in the 3 ' and 5 ' chamber-length conditions to partition the first $30 \mathrm{~cm}$ of runway length nearest the prod from the remaining runway length. The door fit snugly inside the runway, perpendicular to the side walls, and extended from the aluminum floor up through a small slot in the runway ceiling. A thin nylon wire was attached to the top of the door in such a manner that, when it was pulled from an adjacent room, the door would quietly slide straight up through the slot in the runway ceiling. Subjects initially placed in the $30-\mathrm{cm}$ runway segment nearest the prod could not access the remaining length of the runway until the wire was pulled and the door was raised. Thereby, prior to receiving the initial shock, shock-treatment subjects tested in the $3^{\prime}$ and $5^{\prime}$ chamber-length conditions could be restricted to the same 30-cm-long test chamber area nearest the prod, as were subjects testing in the 1 ' condition.

\section{Procedure}

All testing was done between 0800 and $1400 \mathrm{~h}$ in a room separate from the main colony, under dim lighting conditions $\left(0.69 \mathrm{~cd} / \mathrm{m}^{2}\right)$ and with the door to the room closed. The subjects were monitored from an adjacent room via closed-circuit T.V. In order to remove possible residual odors of previously tested subjects, the test chamber was always washed and wiped down with isopropyl alcohol (70\% solution) prior to each test. Each mouse was brought into the testing room and placed in the test chamber of the appropriate length. No habituation period was provided. For subjects tested in the $3^{\prime}$ and $S^{\prime}$ conditions, the sliding door was always in the "lowered" position prior to their introduction into the chamber. These subjects were always placed in the $30-\mathrm{cm}$ long prod-containing end of the test chamber.

For all shock-treated animals, the prod was electrified prior to each subject's being placed in the chamber. These subjects were allowed $60 \mathrm{~min}$ from the time of introduction into the test chamber to make contact with the shock prod. The latency to the initial shock was recorded for each subject. Failure to contact the prod in the allotted time resulted in that animal's being removed from the experiment and replaced by a fresh animal of the same sex, genotype, and group assignment. Few (<5) animals required replacement. Once initially shocked, the subjects were given $15 \mathrm{~min}$ to bury the prod. For subjects tested in the $3^{\prime}$ and 5 ' conditions, the initial contacting of the shock prod also resulted in the virtually simultaneous raising of the sliding door. Thereby, concurrent with the initial shock, these subjects were afforded access to the entire 91- or 152-cm-long areas of their respective test chambers. Once the door was raised, it remained in the "raised" position for the entire 15-min test period. For subjects tested in the $1^{\prime}$ condition, the entire test chamber itself was $30 \mathrm{~cm}$ long; therefore, no sliding door was employed. For all three shock groups, any additional contacts with the shock prod during the 15-min test period also resulted in the animal's being shocked.

The procedure for control subjects was identical to that for shocked animals except that the prod was never electrified. In each chamber-length condition, a control animal was pair-matched to a shocked subject of the same sex, strain, and subline for the amount of time spent in the test chamber. The overall amount of time each control subject spent in the test chamber was equal to the latency-to-shock time of the shocked subject to which it was pairmatched plus the 15-min test period. For control subjects in the 3' and 5 ' conditions, the sliding door was employed, with the amount of time each subject spent in the $30-\mathrm{cm}-1$ long prodcontaining area (door in "lowered" position) being equal to the latency to shock in the respective shocked subject to which it was pair-matched. At the end of the "latency" time, the door was raised and the subject was afforded access to the entire test chamber area for the 15-min test period. Control subjects tested in the 1 ' condition were simply placed in the $30-\mathrm{cm}$ test chamber for an amount of time equal to the latency-to-shock time of the 1 ' condition shocked subject to which it was pair-matched plus the 15-min test period time.

When the 15-min test period for each subject had elapsed, the subject was carefully removed from the test chamber and was not used again. The height of the bedding material accumulated at the point where the prod was mounted on the end wall was then recorded. The highest point of piled bedding in the entire test chamber was also located, and its distance from the prod wall was recorded. The height-at-prod measure was considered indicative of burying magnitude, while the distance-of-highest-point measure was considered indicative of the degree to which maximal bedding displacement was prod-directed. Animals displaying good burying were predicted to show large height-at-prod values concomitant with small distance-of-highest-point values.

Overall differences between groups were determined parametrically and nonparametrically. Analyses of variance were performed for (1) the height of bedding at the prod measure, (2) the distance of the highest point of bedding from the prod-wall measure, and (3) a composite "burying score" that combined each subject's scores for (1) and (2) into one score representative of overall burying performance.' Instead of performing one overall five-way ANOVA (i.e., treatment $\times$ strain $\times$ subline $\times$ sex $\times$ chamber length) on each of these measures, separate four-way ANOVAs (excluding the chamber-length variable) were performed on each measure for each chamber-length condition. This was done because variances across chamber lengths were found to be heterogeneous for each burying measure (Hartley $F_{\max }(79)=2.30,47.94,16.60$, all $p<$ .01 , for height, distance, and burying score measures, respectively). Across chamber length, comparisons were, however, subsequently performed nonparametrically (see below). For each four-way ANOVA, those two sublines of the same strain were nested within each strain. Due to pair-matching treatment and control subjects on sex, subline, strain, and time spent in the test chamber, the shock/no-shock variable was treated as a repeated factor. Posttest comparisons of each shock treatment group with 
its representative pair-matched control group were performed using repeated-measures $t$ tests.

The proportion of subjects that exhibited burying behavior was also determined for each group. Burying or not burying was assessed for each subject on the basis of whether or not that subject met two predetermined criteria. First, the height of bedding piled at the prod had to be at least as high as the top of the prod $(4.0 \mathrm{~cm})$. Second, the highest point of piled bedding had to be within a distance of $5.0 \mathrm{~cm}$ from the prod wall. The first criterion was necessary in order to accurately label a response, in the strict definitional sense, as burying, while the second criterion helped to assure that the response was prod oriented and not merely due to random bedding displacement (Modaresi, 1982). Only subjects meeting both criteria were labeled "buriers." Within and across chamber-length group comparisons of the proportion of subjects meeting both criteria were performed nonparametrically using chisquare analyses and Fisher's exact probability tests (Siegel, 1956).

\section{RESULTS}

The employment of both the height-of-bedding-atthe-prod and the distance-of-highest-point-from-theprod-wall measures (and therefore the overall burying score measure to which they contribute) as valid and interrelated measurements differentiating defensive burying from random bedding displacement is evidenced in two important findings. First, across the three test-chamber conditions, a consistent proportional relationship between the two measures was found for shock-treatment groups but not for nonshocked control groups. Pearson product moment correlations comparing each group's mean height with its mean distance, across all chamber lengths within shock/no-shock treatments, revealed that the two measures were highly related for shocked groups $[\mathrm{r}(10)=-.70, \mathrm{p}<.01]$, but not for control groups $[\mathrm{r}(10)=-.11, \mathrm{p}=\mathrm{n} . \mathrm{s}]$. Second, the distributions of where the highest piles of bedding lay for shocked vs. nonshocked subjects were dramatically different. For shocked subjects, the highest pile of bedding was, by far, most likely to be the actual height at the prod (i.e., 0 distance from prod wall), while the highest piles of bedding for control subjects were distributed much more randomly. These findings indicate that both the distance measure and the bedding height at the prod measure are defensiveburying related, thereby providing strong support for their combined utilization (i.e., burying scores) in distinguishing conditioned defensive burying from random bedding displacement.

\section{Proportion of Subjects Burying}

Of the two criteria used to determine whether individual subjects did or did not bury, the requirement of a 4-cm height of bedding at the prod was clearly the most stringent. Of the 240 mice tested, $67(28 \%)$ met the height-at-the-prod criterion and $81(34 \%)$ met the location-of-highest-point criterion. Sixty-five subjects (27\%) met both criteria and were labeled "buriers." As shown in Table 1, shock had a dramatic effect in determining whether a particular subject did or did not bury. Fifty-nine of the 120 shock-treatment subjects $(49 \%)$ buried the shock prod, while only 6 of the 120 control subjects $(5 \%)$ buried $(p<.001)$. Furthermore, more shocked subjects buried in each of the chamber-length conditions (collapsed on sublines and strains), in each of the two strains (collapsed on subline and chamber length), and in each of the four sublines (collapsed on chamber length) than did control subjects.

In general, burying was found to be more prevalent in mice of the C57 strain than in mice of the DBA strain. Forty-eight of the $120 \mathrm{C} 57$ mice buried, while only 17 of the 120 DBA mice did so $(p<.001)$. Overall strain differences were also observed within each treatment (collapsed on chamber-length conditions). For shocked subjects, 42 of 60 C57s (70\%) and 17 of 60 DBAs $(28 \%)$ buried $(\mathrm{p}<.001)$, while controls, 6 of 60 C57s (10\%) and 0 of 60 DBAs

Table 1

Proportion of Animals Meeting Both Burying Criteria in Shock and Control Conditions

\begin{tabular}{|c|c|c|c|c|c|c|c|c|c|c|c|c|}
\hline \multirow[b]{3}{*}{ Subline } & \multicolumn{12}{|c|}{ Chamber-Length Condition } \\
\hline & \multicolumn{3}{|c|}{$1 \mathrm{ft}$} & \multicolumn{3}{|c|}{$3 \mathrm{ft}$} & \multicolumn{3}{|c|}{$5 \mathrm{ft}$} & \multicolumn{3}{|c|}{ All } \\
\hline & Shock & Control & $\mathrm{p}$ & Shock & Control & $\mathrm{p}$ & Shock & Control & $\mathrm{p}$ & Shock & Control & $\mathrm{p}$ \\
\hline \multicolumn{13}{|c|}{ DBA Strain } \\
\hline D-I & $3 / 10$ & $0 / 10$ & n.s. & $3 / 10$ & $0 / 10$ & n.s. & $3 / 10$ & $0 / 10$ & n.s. & $9 / 30$ & $0 / 30$ & .001 \\
\hline D-H & $8 / 10$ & $0 / 10$ & .001 & $0 / 10$ & $0 / 10$ & n.s. & $0 / 10$ & $0 / 10$ & n.s. & $8 / 30$ & $0 / 30$ & .003 \\
\hline $\mathrm{C} 10$ & $8 / 10$ & $3 / 10$ & .04 & $9 / 10$ & $1 / 10$ & .001 & $2 / 10$ & $0 / 10$ & n.s. & $19 / 30$ & $4 / 30$ & .001 \\
\hline $\mathrm{C}-\mathrm{Y}$ & $9 / 10$ & $1 / 10$ & .001 & $7 / 10$ & $0 / 10$ & .002 & $7 / 10$ & $1 / 10$ & .01 & $23 / 30$ & $2 / 30$ & .001 \\
\hline Both & $17 / 20$ & $4 / 20$ & .001 & $16 / 20$ & $1 / 20$ & .001 & $9 / 20$ & $1 / 20$ & .004 & $42 / 60$ & $6 / 60$ & .001 \\
\hline \multicolumn{13}{|c|}{ Both Strains } \\
\hline All & $28 / 40$ & $4 / 40$ & .001 & $19 / 40$ & $1 / 40$ & .001 & $12 / 40$ & $1 / 40$ & .001 & $59 / 120$ & $6 / 120$ & .001 \\
\hline
\end{tabular}

Note-Ratios consist of the number of subjects meeting both criteria over the total number tested. Probability (p) values for differences between the shock and control groups were derived via the Fisher exact probability test (Siegel, 1956); $p$ is less than the value given (n.s. indicates $p>.05)$. 
$(0 \%)$ buried $(p<.02)$. Significantly more C57 mice also buried within each chamber-length condition (collapsed on treatments, $\mathrm{p}_{1}<.02, \mathrm{p}_{3}<.001$, $\mathrm{p}_{5}<$ .03). Although in each chamber-length condition more shocked C57 mice buried than did shocked DBAs $\left(\mathrm{p}_{1}<.03, \mathrm{p}_{3}<.001, \mathrm{p}_{5}<.04\right)$, strain differences in the number of control subjects burying within each chamber-length condition were not observed.

The incidence of defensive burying was also influenced by test-chamber length. Twenty-eight of the 40 shock-treatment subjects tested in the 1 ' condition $(70 \%)$ buried the prod, while only 19 of the 40 tested in the $3^{\prime}$ condition $(47.5 \%)$ and 12 of the 40 tested in the $5^{\prime}$ condition $(30 \%)$ did so. Thus, the overall number of shocked subjects that buried decreased as a function of an increase in test chamber size $\left[\chi^{2}(2)=\right.$ $12.86, \mathrm{p}<.005$ ]. Test-chamber length had no effect, however, on the number of control subjects that buried. It is worth noting that, in attempting to control for shock-latency differences across the three test-chamber-length conditions (via employing a sliding door in the $3^{\prime}$ and $5^{\prime}$ chamber-length conditions but not in the $1^{\prime}$ condition), a potential confound may have been created. However, inasmuch as the proportion of shock-treatment subjects displaying burying decreased as a function of each chamberlength increase, the potentially confounding effects of using a sliding door in only $3^{\prime}$ and $5^{\prime}$ conditions appear to be incidential to the overall effect of increasing the chamber length. That the proportion of control subjects that buried did not differ across chamber-length conditions (even though the sliding door was similarly used in the $3^{\prime}$ and $5^{\prime}$, but not the $1^{\prime}$ condition) further suggests that the effect of the sliding door on burying was minimal.

Overall, males and females were equally likely to display burying, regardless of treatment. Twentyseven of the 60 shock-treatment males buried the shock prod and 32 of the 60 similarly treated females did so $(p=n . s$.). Three control males and 3 control females of the 60 of each tested displayed burying. Within each strain or subline, no sex differences in the number of subjects that buried were observed for either shock or control treatments of any test chamber condition.

Within each strain, subline-dependent and chamber-length-dependent differences in shockelicited burying prevalence were observed. As shown in Figure 1, a high percentage of C57 mice of both sublines buried the shock prod in the $1^{\prime}$ and $3^{\prime}$ conditions. However, in the $5^{\prime}$ condition, a high incidence of buriers was observed in the C-Y subline only. Significantly more subjects of the C-Y subline displayed shock-elicited burying in the $S^{\prime}$ condition than did C10 subjects $(p<.032)$, with the incidence of burying in the latter group being comparable to that of its respective control group $(p=n$.s.).

In contrast to the overall high incidence of shockelicited burying in the C57 strain, only one subline of the DBA strain demonstrated a high incidence of burying, and only in one chamber-length condition. Eighty percent of the D-H mice displayed shockelicited burying in the $1^{\prime}$ condition, while none buried in the $3^{\prime}$ and $5^{\prime}$ conditions. Few D-I mice buried, regardless of the size of the test chamber. Probability values associated with subline differences in the number of subjects displaying shock-elicited burying are given in Table 2 . Both within and across chamber-length conditions, no reliable differences among sublines in the number of control subjects that buried were observed.

\section{Burying Magnitude and Directionality}

The results of the four-way ANOVAs performed on the burying magnitude, directionality, and burying score measures are summarized in Table 3. Except for the distance measure of the 5' chamberlength condition, main effects for treatment (i.e., shock vs. no shock) were obtained for all measures of every chamber-length condition. For each measure in which main effects for treatment were observed,

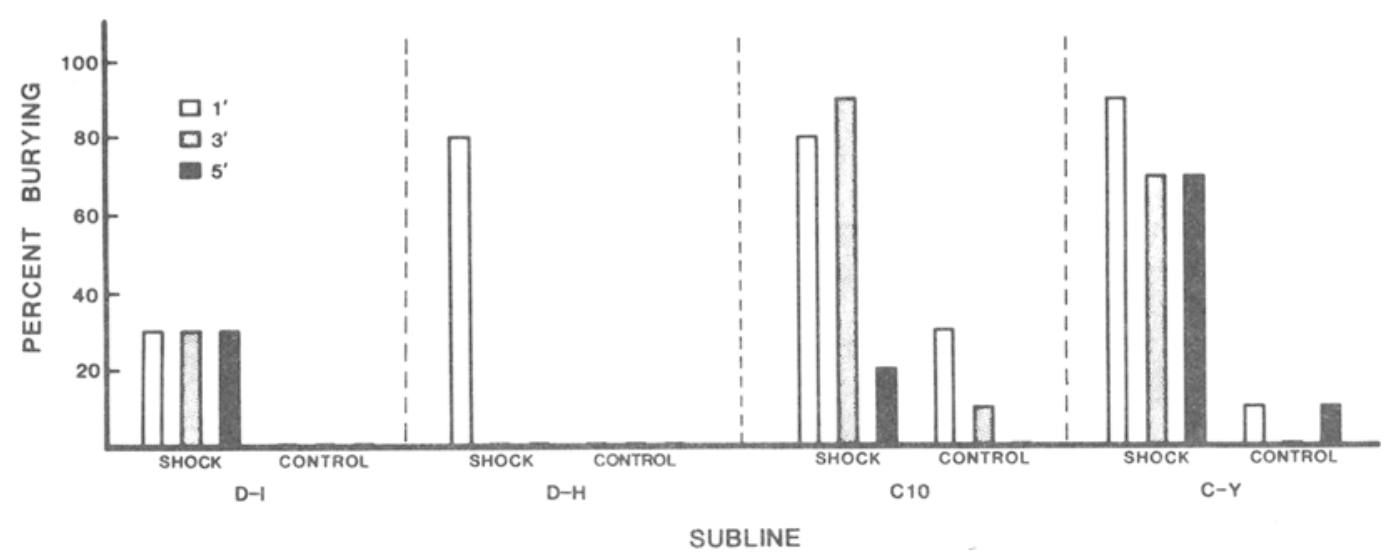

Figure 1. Percent of shock and control subjects of each subline that buried in each test-chamber-length condition. 
Table 2

Probabilties Associated With Group Differences in the Number of Shocked Subjects Meeting Both Bury ing Criteria

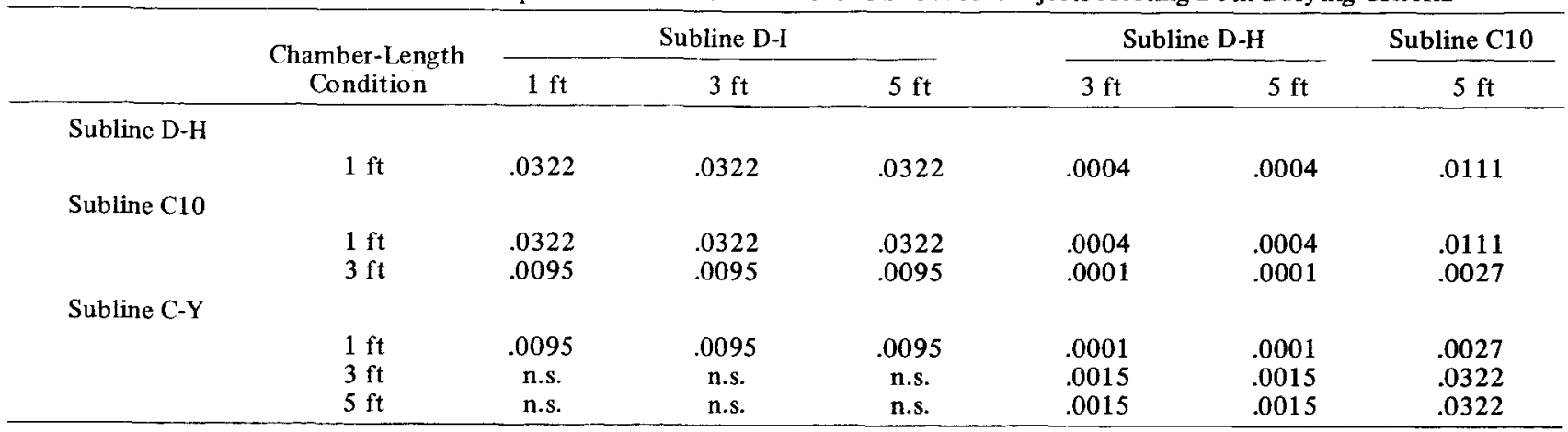

Note-Tabled values reflect the probability (Fisher exact probability test) that the observed number of buriers for the group labeled to the left was greater than the observed number of buriers for the group labeled above. Group comparisons that resulted in calculated $p$ values greater than .05 were omitted or are indicated by n.s. (= nonsignificant).

shocked animals displayed better burying (i.e., larger height values, smaller distance values, smaller burying scores) than nonshocked controls. Main effects for strain were also observed and were obtained for all measures of every chamber-length condition except the $1^{\prime}$ and $5^{\prime}$ distance measures. The obtained strain differences were always attributable to C57 mice displaying better burying than DBA mice. Main effects for subline were also obtained for each measure of burying, but only in the 5 ' chamber-length condition. Main effects for sex were never observed.

Aside from the previously described findings obtained by the direct nonparametric comparisons of the proportion of subjects meeting burying criteria, the interactively dependent relationship of subline

Table 3

ANOVA for Burying Measures

\begin{tabular}{|c|c|c|c|}
\hline \multirow[b]{2}{*}{ Variable } & \multicolumn{3}{|c|}{ Chamber-Length Condition } \\
\hline & $1 \mathrm{ft}$ & $3 \mathrm{ft}$ & $5 \mathrm{ft}$ \\
\hline \multicolumn{4}{|c|}{ Burying Score } \\
\hline Treatment & $72.34 * *$ & $26.24 * * *$ & 4.73 \\
\hline Strain & $10.64 * *$ & $12.91 * *$ & $7.55 * *$ \\
\hline Subline & n.s. & n.s. & $9.22 * * *$ \\
\hline \multicolumn{4}{|c|}{ Height } \\
\hline Treatment & $80.32 * * *$ & $46.33 * * *$ & $21.34 * * *$ \\
\hline Strain & $16.38 * *$ & $12.95 * *$ & $12.78 * *$ \\
\hline Subline & n.s. & n.s. & $4.96^{*}$ \\
\hline Treatment $\times$ Strain & n.s. & $7.15^{*}$ & n.s. \\
\hline Treatment $\times$ Subline & $3.85^{*}$ & n.s. & n.s. \\
\hline \multicolumn{4}{|c|}{ Distance } \\
\hline Treatment & $40.21 * * *$ & $7.00^{*}$ & n.s. \\
\hline Strain & n.s. & $7.06^{*}$ & n.s. \\
\hline Subline & n.s. & n.s. & $5.07 *$ \\
\hline Treatment $\times$ Sex & n.s. & $5.56^{*}$ & n.s. \\
\hline
\end{tabular}

Note $-A$ separate four-way ANOVA (treatment $\times$ strain $\times$ subline $X$ sex) was performed on each measure of each chamberlength condition. F ratios of only those variables found to be statistically reliable $(p<.05)$ are shown.

${ }^{*} p<.05 . \quad{ }^{* *} p<.01 . \quad{ }^{* *} p<.001 . \quad$ n.s. $=$ nonsignificant . and chamber length can also be demonstrated for overall measures of burying magnitude and directionality. Table 4 shows each subline's treatment and control group's mean value on each burying measure of each chamber-length condition. Groups were coded (control groups coded in bold italic type) so that, for clarity, the eight group means obtained for each measure of each chamber-length condition could be respectively ordered on burying performance. It is worth noting that the rankordered positions of the eight groups tended to be maintained across all three chamber-length conditions (Kendall's coefficient of concordance, $\mathbf{W}$, performed on the ranks of group mean burying scores = $.815, \mathrm{p}<.02, \mathrm{df}=7$ ). Thus, the relative burying performance of a group in one chamber-length condition tended also to be reflected at other chamber lengths.

The general finding of a maintenance of rankordered position across test-chamber conditions does not imply that group burying performance was unaffected by test-chamber length. In fact, chamber length was an important determinant of shockelicited burying for some sublines, but had less of an effect on other sublines. By comparing each subline's shock-treatment group with its respective pairmatched control group and by examining changes in their relationship across chamber-length conditions, the differential effects of chamber length on sublines can be assessed for each burying measure. Table 4 shows that (1) the likelihood of obtaining withinsubline differences between treatment and control groups decreased as a function of increasing the testchamber length, and (2) chamber length increases differentially affected some sublines more than others (as measured by differential changes in withinsubline treatment and control group statistical relationships). Furthermore, when group burying performance is considered in the context of the two 
Table 4

Ordered Means for Burying Measures

\begin{tabular}{|c|c|c|c|c|c|c|c|c|c|}
\hline Measure & & \multicolumn{4}{|c|}{ Shock Treatment } & \multicolumn{4}{|c|}{ Control Treatment } \\
\hline \multicolumn{10}{|c|}{ 1-ft Chamber-Length Condition } \\
\hline Burying Score & $\begin{array}{l}\text { Code } \\
\text { Mean }\end{array}$ & $\begin{array}{c}5 \\
17.92\end{array}$ & $\begin{array}{c}6 \\
16.56\end{array}$ & $\begin{array}{c}8 \\
15.77\end{array}$ & $\begin{array}{c}7 \\
12.33\end{array}$ & $\begin{array}{r}1 * * \\
9.62\end{array}$ & $\begin{array}{r}2 * * \\
6.66\end{array}$ & $\begin{array}{r}3 * * \\
4.76\end{array}$ & $\begin{array}{l}4 * * * \\
2.52\end{array}$ \\
\hline Height at Prod & $\begin{array}{l}\text { Code } \\
\text { Mean }\end{array}$ & $\begin{array}{l}5 \\
1.65\end{array}$ & $\begin{array}{l}6 \\
1.69\end{array}$ & $\begin{array}{l}8 \\
2.10\end{array}$ & $\begin{array}{l}7 \\
3.23\end{array}$ & $\begin{array}{l}1 * \\
3.41\end{array}$ & $\begin{array}{l}2 * * * \\
4.47\end{array}$ & $\begin{array}{l}3 * * * \\
4.83\end{array}$ & $\begin{array}{l}4 * * * \\
5.53\end{array}$ \\
\hline \multicolumn{10}{|c|}{ 3-ft Chamber-Length Condition } \\
\hline Burying Score & $\begin{array}{l}\text { Code } \\
\text { Mean }\end{array}$ & $\begin{array}{c}6 \\
59.96\end{array}$ & $\begin{array}{c}5 \\
55.11\end{array}$ & $\begin{array}{c}8 \\
53.72\end{array}$ & $\begin{array}{c}2 \\
51.82\end{array}$ & $\begin{array}{c}7 \\
48.19\end{array}$ & $\begin{array}{c}1 \\
35.88\end{array}$ & $\begin{array}{r}4 * * \\
25.68\end{array}$ & $\begin{array}{r}3 * * \\
19.15\end{array}$ \\
\hline Height at Prod & $\begin{array}{l}\text { Code } \\
\text { Mean }\end{array}$ & $\begin{array}{l}6 \\
1.61\end{array}$ & $\begin{array}{l}7 \\
1.94\end{array}$ & $\begin{array}{l}8 \\
1.94\end{array}$ & $\begin{array}{l}5 \\
2.12\end{array}$ & $\begin{array}{r}2 * * \\
2.95\end{array}$ & $\begin{array}{l}1^{*} \\
3.09\end{array}$ & $\begin{array}{r}3 * * \\
4.44\end{array}$ & $\begin{array}{l}4^{* * *} \\
4.74\end{array}$ \\
\hline Burying Score & $\begin{array}{l}\text { Code } \\
\text { Mean }\end{array}$ & $\begin{array}{c}2 \\
104.63\end{array}$ & $\begin{array}{c}6 \\
93.39\end{array}$ & $\stackrel{5}{75.65}$ & $\begin{array}{c}7 \\
74.89\end{array}$ & $\begin{array}{c}8 \\
65.28\end{array}$ & $\begin{array}{c}3 \\
64.37\end{array}$ & $\begin{array}{c}1 * \\
43.24\end{array}$ & $\stackrel{4}{30.75}$ \\
\hline Height at Prod & $\begin{array}{l}\text { Code } \\
\text { Mean }\end{array}$ & $\begin{array}{l}6 \\
1.46\end{array}$ & $\begin{array}{l}2 \\
2.28\end{array}$ & $\begin{array}{l}5 \\
2.32\end{array}$ & $\begin{array}{l}7 \\
2.60\end{array}$ & $\begin{array}{l}8 \\
2.70\end{array}$ & $\begin{array}{l}3 \\
3.12\end{array}$ & $\begin{array}{l}1 * \\
3.17\end{array}$ & $\begin{array}{l}4^{*} \\
4.18\end{array}$ \\
\hline $\begin{array}{l}\text { Distance of } \\
\text { Highest Mound }\end{array}$ & $\begin{array}{l}\text { Code } \\
\text { Mean }\end{array}$ & $\begin{array}{c}2 \\
107.40\end{array}$ & $\begin{array}{c}6 \\
58.49 \\
\end{array}$ & $\begin{array}{c}7 \\
57.67 \\
\end{array}$ & $\begin{array}{c}5 \\
50.33 \\
\end{array}$ & $\begin{array}{c}8 \\
41.63\end{array}$ & $\begin{array}{c}3 \\
41.33 \\
\end{array}$ & $\begin{array}{c}4 \\
19.56\end{array}$ & $\begin{array}{c}1 \\
12.50\end{array}$ \\
\hline
\end{tabular}

Note-For each measure, groups are ordered from worst (left) to best (right). Control groups' codes are indicated in bold italics. For each measure of each chamber-length condition, $t$ tests comparing each subline's shock treatment group with its respective pairmatched control group were performed. Probabilities (two-tailed) associated with these group differences are indicated next to the shocked group's respective code. ${ }^{*} p<.05 .{ }^{* *} p<.01 .{ }^{* * *} p<.001$.

burying criteria (i.e., height $>4.0 \mathrm{~cm}$, distance $<$ $5.0 \mathrm{~cm}$ ), the differential effect on sublines of increasing the chamber length becomes even more evident.

As shown in Figure 2, the length of the test chamber had little overall effect on shock-elicited burying by the D-I subline. The mean bedding heights at the prod were consistently poor in all chamber-length conditions (all were below the prod height), and the mean distances of the highest mound of bedding from the prod were relatively consistent across chamber lengths. Conversely, the shock-elicited burying by the D-H subline was adversely affected by each increase in the length of the test chamber. Hierarchical decreases in both the magnitude and directionality of burying, resulting from increased test chamber length, were observed. Interestingly, the overall burying score of the D-H shocked group ranked poorest of all groups tested in the $5^{\prime}$ condition (Table 4).

While the burying by the D-H subline was detrimentally affected by each increase in chamber length, the C10 subline was primarily affected by the chamber-length difference between the $3^{\prime}$ and $5^{\prime}$ conditions (Figure 2). Table 4 shows that, in the 1' and $3^{\prime}$ conditions, the $\mathrm{C} 10$ shocked groups were reliably better in overall burying than their pairmatched controls while, in the $5^{\prime}$ condition, the $\mathrm{C} 10$ shocked group was statistically equivalent to its con- trol group. In contrast, shocked mice of the C-Y subline displayed good burying in all three chamberlength conditions (although in the $5^{\prime}$ condition the $C$ $Y$ shocked group did not statistically differ from its pair-matched control group, primarily because of an elevated level of unconditioned burying in the latter).

The profound effect of chamber-length increases on burying were surpassed only by the effect of shock. For the 120 shocked subjects (collapsed on chamber-length conditions and sublines), the mean bedding height at the prod was found to be above the diametric center of the prod (mean height $=3.85$ $\pm .28 \mathrm{~cm}$ ), whereas the overall mean for controls was approximately equal to the initial bedding height (mean height $=2.11 \pm .15 \mathrm{~cm}$ ). Shocked subjects were also slightly better, overall, in burying directionality (mean distance from prod for shock groups $=23.08 \pm 8.90 \mathrm{~cm}$; for controls $=34.78 \pm 5.31 \mathrm{~cm}$ ). Furthermore, Table 4 shows that, with the exception of the D-H subline shocked in the $3^{\prime}$ and $5^{\prime}$ conditions, in each chamber-length condition every shocked group ranked better in burying performance on every measure than any nonshocked group. Not only did shock result in increased bedding heights at the prod (Figure 2), for shocked subjects the pile of bedding accumulated at the prod was most likely to be the highest pile in the entire chamber (i.e., 0 distance from the prod wall). As shown in Figure 3, the 

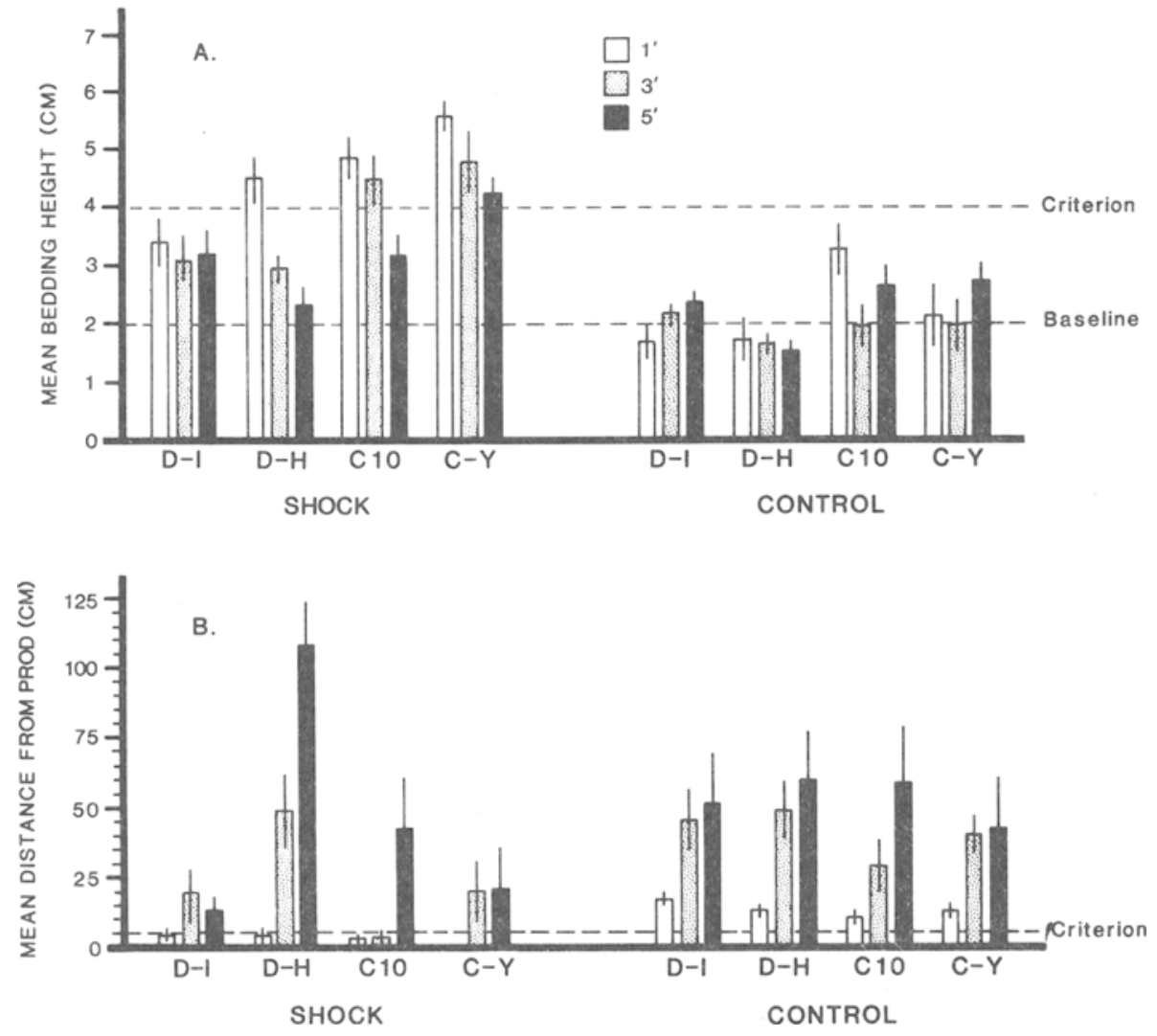

Figure 2. Mean heights of bedding material at the prod $\pm \mathrm{SE}$ (A) and mean distances of the highest pile of bedding from the prod wall $\pm S E(B)$ for each subline, in each chamber-length condition, under shock and nonshocked control treatments.
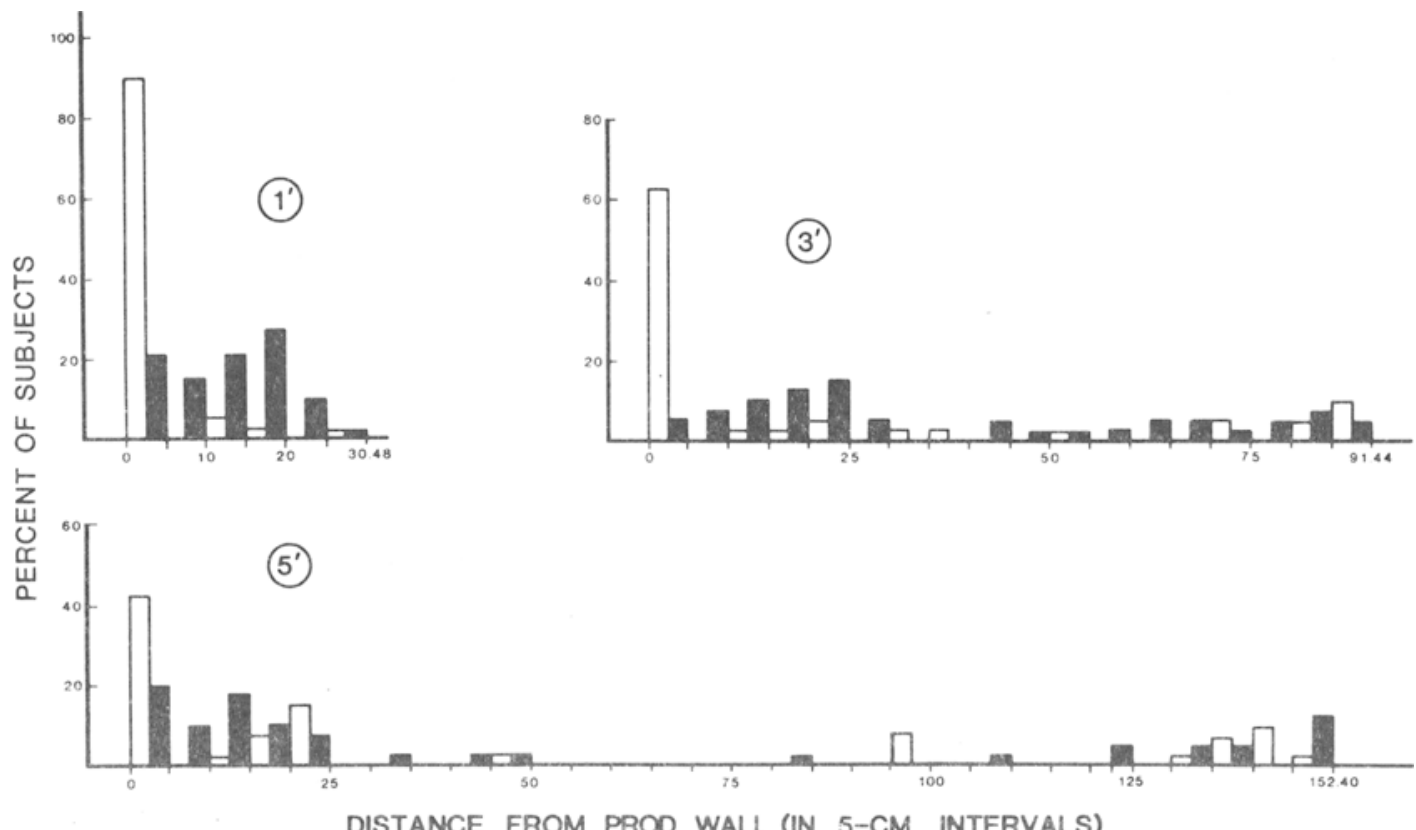

DISTANCE FROM PROD WALL (IN 5-CM. INTERVALS)

Figure 3. Percent of shock, $\square$, vs. control, $\square$, subjects of each chamber-length condition that had the highest pile of bedding located in each 5-cm distance interval from the prod wall. 
highest pile of bedding for shocked subjects tended to be located within the $5 \mathrm{~cm}$ nearest the prod, whereas for controls the highest piles were much less prod oriented.

\section{DISCUSSION}

The results of the present experiment strongly emphasize the importance of considering both genotype and environment as interactive influences on the defensive-burying response of mice. Of the four sublines we examined, the D-I subline displayed relatively poor defensive burying in all chamber-length conditions (i.e., comparable to nonshocked controls in the proportion of buriers), the D-H subline buried only in the $1^{\prime}$ condition, the $\mathrm{C} 10$ subline buried in the $1^{\prime}$ and $3^{\prime}$ conditions but not in the $5^{\prime}$ condition, and the $\mathrm{C}$-Y subline displayed relatively good burying in every chamber-length condition. Thus, with regard to burying incidence, each subline was differentially affected by the three chamber-length conditions. Parametric analyses of magnitude and directionality measures yielded similar results (cf. D-I $1^{\prime}$ and $5^{\prime}$ measures, C-Y S' measures, Table 4).

Previous investigations examining the effects on defensive burying of increasing the dimensions of the test chamber have proven inconclusive. Some investigators have found defensive burying to be unaffected by chamber size (Peacock \& Wong, 1982; Poling et al., 1981), whereas others have reported that certain chamber-size increases reduce, but do not abolish, burying (Davis, Moore, et al., 1982; Pinel, Treit, Ladak, \& MacLennan, 1980). Overall, the present results indicate that increasing the length dimension of the test chamber alone can have a substantial detrimental effect on defensive burying. Collapsing on sublines, we found that the magnitude of burying, the directionality of burying, and the proportion of subjects displaying burying all were adversely affected by each chamber length increase. These findings support the previous reports by Pinel, Treit, Ladak, and MacLennan (1980) and Davis, Moore, et al. (1982) of chamber-size-dependent effects on burying, and extend their findings in a number of important ways. First, we have shown that mice, along with rats (Pinel, Treit, Ladak, \& MacLennan, 1980) and gerbils (Davis, Moore, et al., 1982) can also be adversely affected by increasing the test-chamber dimensions. Second, since the width of our test chambers remained unchanged throughout the three length conditions we examined (i.e., $9.3 \mathrm{~cm}$ ), our results indicate that increasing the length dimension alone is sufficient to reduce defensive burying. Third, the present results provide the first evidence that defensive burying can be virtually abolished by increasing the dimensions of the test chamber.

In light of four previous investigations, in which both the length and width dimensions (or diameter in round chambers) of test chambers were increased and burying was not abolished (Davis, Moore, et al., 1982; Peacock \& Wong, 1982; Pinel, Treit, Ladak, \& MacLennan, 1980; Poling et al., 1981), one possible reason for the positive findings we obtained by increasing only the length of the test chamber is that, relative to the size of the subjects employed, the accessible distances afforded subjects for flight in the present experiment were considerably greater than those afforded subjects in previous paradigms. Of the four prior investigations, only Pinel, Treit, Ladak, and MacLennan (1980) provided subjects a maximal distance for flight from the shock prod that was greater than our longest chamber-length condition (215.41 vs. $152.40 \mathrm{~cm}$, respectively). However, they employed rats as subjects, whereas our subjects were mice. Thus, when the size differences between our subjects and those employed by other investigators are taken into account, our $3^{\prime}$ and $5^{\prime}$ chamber-length conditions afforded subjects a relatively greater maximal distance for flight (approximately 15 and 20 times their snout-to-rump body lengths, respectively) than any test chamber previously employed. Since the floor-surface-area/subject-body-size ratios of the present experiment were comparable to those ratios employed by other investigators, the relative distance for flight, rather than the relative overall size of the test chamber, is implicated. This interpretation, although speculative, is in accordance with our finding that chamber length increases alone are sufficient to reduce and/or abolish burying and is also compatible with previous findings (Davis et al., 1981; Treit et al., 1980) demonstrating that mice spend less time defensively burying than do rats when both are tested in the same experimental chambers. Such an interpretation also suggests that in prior investigations in which chamber-size increases failed to reduce (Peacock \& Wong, 1982; Poling et al., 1981) or abolish (Davis, Moore, et al., 1982; Pinel, Treit, Ladak, \& MacLennan, 1980) burying, the provided accessible distances for flight may not have been great enough, even though the overall sizes of the test chambers were greatly increased. Indeed, even in the present experiment, in which large relative distances for flight were provided, the C-Y subline continued to display substantial burying.

Exactly how great a distance for flight is necessary in order to reduce or abolish burying appears to depend not only on the relative distance available for flight, but also on the specific genotype of subjects. This position is emphasized in the present experiment in that within the species Mus musculus, and even within specific strains of that species, different flight distances were necessary to reduce and abolish burying. Worth noting, however, is that sublines within each strain were more similar in overall burying performance than were sublines of different strains. Neither DBA subline buried at a chamber length at which both C57 sublines were still displaying good 
burying. Thus, the degree of genotypic similarity among sublines was evidenced phenotypically in burying performance.

When taken collectively, the results of the present experiment indicate that labeling defensive burying (or any defensive response; Bolles, 1970) as species specific may be a misleading oversimplification which underemphasizes within-species and withinstrain environmentally dependent variations in the display of the response. Rather than considering defensive burying as a species-specific response to aversive stimulation in general (Pinel \& Treit, 1978), the present findings of chamber-length-dependent defensive-burying differences between strains and even between sublines of the same strain indicate that defensive burying should more appropriately be viewed as a genotypically dependent response, the display of which is contingent on the specific environmental context in which an aversive stimulus is encountered.

The present experiment also poses interesting questions regarding the employment of defensive burying by rodents in naturalistic settings, especially in situations where unlimited distances for flight are available. Although Pinel, Treit, Ladak, and MacLennan (1980) have argued that "defensive burying is not restricted to situations in which flight is impossible" (p. 450), defensive burying, in a strict definitional sense (Modaresi, 1982), has yet to be observed in unrestricted natural settings in which animals have unlimited directions and distances for flight. Our observations with mice suggest that under such circumstances a flight/avoidance strategy, rather than a defensiveburying strategy, might be more likely to occur. This interpretation does not, however, preclude the possibility that animals may commonly employ a defensive burying or "spraying"' (Modaresi, 1982) strategy when they are cornered by predators or are defending resources (e.g., food, burrows, young). In fact, the results of the present and previous experiments (Davis, Moore, et al., 1982; Pinel, Treit, Ladak, \& MacLennan, 1980) indicate that these and similar circumstances (Owings, Borchert, \& Virginia, 1977; Owings \& Coss, 1978) may potentiate the utilization of a burying strategy by requiring animals to remain in relatively close proximity to the aversive stimulus.

\section{REFERENCE NOTE}

1. Maxon, S. C. Personal communication, June 21, 1982.

\section{REFERENCES}

Bolles, R. C. Species specific defense reactions and avoidance learning. Psychological Review, 1970, 77, 32-48.

Davis, S. F., Moore, S. A., Cowen, C. L., Thunston, D. K., \& Magato, J. C. Defensive burying in the Mongolian gerbil (Meriones unguiculatus) as a function of size and shape of the test chamber. Animal Learning \& Behavior, 1982, 10, 516-520.

Davis, S. F., Whiteside, D. A., Dickson, V. A., Heck, D. G., \& MCKNAB, P. A. Conditioned defensive burying as a func- tion of stimulus modality and stimulus accessibility. Journal of General Psychology, 1982, 106, 101-108.

Davis, S. F., Whiteside, D. A., Heck, D. G., Dickson, V. A., \& Tramill, J. L. Defensive burying: A cross-species replication and extension. Bulletin of the Psychonomic Society, 1981, 7, 45-47.

Gingeurg, B. E., Vigue, L. C., Largon, W. A., \& Maxgon, S. C. Y-chromosome length in sublines of two mouse strains. Behavior Genetics, 1981, 11, 359-368.

Holland, P. C. Conditioned stimulus as a determinant of the form of the Pavlovian conditioned response. Journal of Experimental Psychology: Animal Behavior Processes, 1977, 3, 77-104.

Hudson, B. B. One-trial learning in the domestic rat. Genetic Psychology Monographs, 1950, 41, 99-145.

Maxson, S. C., Ginsbura, B. E., \& Thattner, A. Interaction of Y-chromosomal and autosomal gene(s) in the development of intermale aggression in mice. Behavior Genetics, 1979, 9, 219-226.

McKim, W. A., \& LETT, B. T. Spontaneous and shock-induced burying in two strains of rats. Behavioral \& Neural Biology, $1979,26,76-80$.

Modaresi, H. A. Defensive behavior of the rat in a shock-prod situation: Effects of the subject's location preference. Animal Learning \& Behavior, 1982, 10, 97-102.

Owings, D. H., Borchert, M., \& Virginia, R. The behavior of California ground squirrels. Animal Behaviour, 1977, 25, 221-230.

Owings, D. H., \& Coss, R. G. Snake mobbing by California ground squirrels: Adaptive variation and ontogeny. Behaviour, $1978,62,50-69$.

Peacock, E. J., \& Wong, P. T. P. Defensive burying in the rat: A behavioral field analysis. Animal Learning \& Behavior, 1982 , 10, 103-107.

Pinel, J. P. J., Hoyen, E., \& Terleck1, L. J. Defensive burying and approach-avoidance behavior in the rat. Bulletin of the Psychonomic Society, 1980, 16, 349-352.

Pinel, J. P. J., \& Treit, D. Burying as a defensive response in rats. Journal of Comparative and Physiological Psychology, $1978,92,708-712$.

Pinel, J. P. J., \& Treit, D. Conditioned defensive burying in rats: Availability of burying materials. Animal Learning \& Behavior, 1979, 7, 392-396.

Pinel, J. P. J., Treit, D., Ladak, F., \& Maclennan, A. J. Conditioned defensive burying in rats free to escape. Animal Learning \& Behavior, 1980, 8, 447-451.

Pinel, J. P. J., Treit, D., \& Wilkie, D. M. Stimulus control of defensive burying in the rat. Learning Motivation, 1980, 11, 150-163.

Poling, A., Clenty, J., \& Monaghan, M. Burying by rats in response to aversive and nonaversive stimuli. Journal of the Experimental A nalysis of Behavior, 1981, 35, 31-44.

Siegel, S. Nonparametric statistics. New York: McGraw-Hill, 1956.

Selmanoff, M. K., Maxson, S. C., \& Gingeuro, B. E. Chromosomal determinants of intermale aggressive behavior in inbred mice. Behavior Genetics, 1976, 6, 53-69.

TARTE, R. D., \& Oberdieck, F. Conditioned defensive burying in rats as a function of pre-exposure and strain. Psychological Record, 1982, 32, 101-107.

Terlecki, L. J., Pinel, J. P. J., \& Treit, D. Conditioned and unconditioned defensive burying in the rat. Learning \& Motivation, 1979, 10, 337-350.

Treit, D., Terlecki, L. J., \& Pinel, J. P. J. Conditioned defensive burying in rodents: Organismic variables. Bulletin of the Psychonomic Society, 1980, 16, 451-454.

Whillans, K. V., \& Shettle worth, S. J. Defensive burying in rats and hamsters. Animal Learning Behavior, 1981, 9, 357-362.

Wilkie, D. M., Maclennan, J. A., \& Pinel, P. J. Rat defensive behavior: Burying noxious food. Journal of the Experimental Analysis of Behavior, 1979, 31, 299-306. 


\section{NOTE}

1. Burying scores for each subject were derived via the formula:

$$
\text { Burying score }_{x_{n}}=\frac{\left(H_{x_{\max }}-H_{x_{n}}\right)\left(\frac{D_{x_{\max }}-D_{x_{\min }}}{H_{x_{\max }}-H_{x_{\min }}}\right)+D_{x_{n}}}{2} \text {, }
$$

where $n=$ the subject, $\mathrm{x}=$ the chamber length that the subject was tested in, $\mathrm{H}=$ the height of bedding accrued at the prod, $\mathrm{D}=$ the distance the highest mound of bedding was from the prod, $H_{x_{\max }}$, $\mathbf{H}_{\mathbf{x}_{\min }}=$ the maximum and minimum $\mathbf{H}$ values in $\mathbf{x}$, and $\mathbf{D}_{\mathbf{x}_{\max }}$, $D_{x_{\min }}=$ the maximum and minimum $\mathbf{D}$ values in $\mathbf{x}$. This formula incorporates each subject's height and distance scores into one value representative of both. By taking into account two buryingrelevant measures, the resulting value, or "burying score," pro- vides a more accurate indicant of burying performance than either the height or distance measure alone could provide. The formula is designed to transform each subject's height value to the distance scale, although the reverse can easily be accomplished by interchanging Ds and Hs. Each transformed height value is then summed with that subject's corresponding distance score. Division by 2 is optional and was done to make the burying score values less unwieldy. For our purposes, we employed the formula in such a manner that the resulting burying score for any subject (n) was relative to only those subjects tested in the same chamber-length condition $(x)$. One could, however, determine each subject's relative burying performance across any or all conditions simply by specifying " $x$ " as the limiting condition of interest and then proceeding accordingly.

(Manuscript received June 29, 1982; revision accepted for publication March 3, 1983.) 